Review Article

\title{
Inconclusive Predictions and Contradictions: A Lack of Consensus on Seed Germination Response to Climate Change at High Altitude and High Latitude
}

\author{
Ganesh K. Jaganathan ${ }^{1}$ and Sarah E. Dalrymple ${ }^{2}$ \\ ${ }^{1}$ Institute of Biothermal Technology, University of Shanghai for Science and Technology, Shanghai 20009, China \\ ${ }^{2}$ School of Natural Sciences and Psychology, Liverpool John Moores University, James Parsons Building, Byrom Street, \\ Liverpool L3 $3 A F, U K$
}

Correspondence should be addressed to Ganesh K. Jaganathan; jganeshcbe@gmail.com

Received 31 October 2015; Revised 4 February 2016; Accepted 6 March 2016

Academic Editor: Guang S. Zhou

Copyright @ 2016 G. K. Jaganathan and S. E. Dalrymple. This is an open access article distributed under the Creative Commons Attribution License, which permits unrestricted use, distribution, and reproduction in any medium, provided the original work is properly cited.

\begin{abstract}
Climate change directly affects arctic-alpine plants and acute responses to increased temperatures may be seen in their reproductive fitness and germination ability. However, uncertainties prevail in predicting whether a future warmer climate favors or hampers seed germination in high latitude and high altitude soils and seed germination research in such systems has not been able to provide generalizable patterns of response. The available literature on this subject has been conducted at various locations contributing to difficulties in predicting the response of arctic-alpine seeds to climate change. Here, we show that discrepancies in seed collection, dormancy breaking treatments, and germination conditions found in the published literature are possible reasons for our inability to draw large scale conclusions. We explore how these factors influence the results and highlight the fact that many of the previous investigations have reported the effects of warmer temperature, rather than a warmer climate and all the associated complex environmental interactions, on seed germination. We recommend that long-term monitoring of seed response to treatments that mimic the present and future alpine climate is likely to produce more ecologically meaningful insights and suggest several practical steps that researchers can take that would facilitate greater coherence between studies.
\end{abstract}

\section{Introduction}

Germination is one the most critical events in the life-cycle of many plants around the world [1]. Germination usually begins immediately in nondormant seeds after suitable temperature and moisture are available $[1,2]$. However, dormant seeds delay germination and often use the unsuitable climatic conditions to break dormancy and germinate during the growing season [3]. By producing seeds that can synchronize the timing of germination to the most favorable period of the year, plants can bet-hedge against unpredictably variable environments $[4,5]$. Such a highly complex trait has been acting as a selective evolutionary pressure resulting from climatic variation over millions of years [5]. As a consequence, some species find a particular habitat more suitable, whilst other habitats become detrimental for seed germination and continued plant growth. The suitable environment allows the persistence of those adapted species to germinate, grow, and reproduce, thus maintaining species abundance. However, this adaptation has been undergoing a rapid transformation in recent years, predominantly due to the effects of global warming bringing significant changes to climatic conditions $[6,7]$. It has been estimated that the earth's surface temperature has risen by $0.6^{\circ} \mathrm{C}$ over the past 100 years and the projections for future warming suggested an alarming $2^{\circ} \mathrm{C}$ in this century $[8,9]$. These discussions have stimulated a plethora of studies focusing on the germination capacity of seeds at ecosystem levels $[10,11]$ or of different life-forms [8]. 
It is becoming clear that the effects of global warming are vegetation specific $[12,13]$. For example, in the tropics and fire-prone environments, the increased summer temperatures are likely to result in long and high summer temperature along with more frequent or high intensity fire, altering the germination and persistence of many species $[14,15]$. In contrast, the temperate regions might experience more nonseasonal rainfall and prolonged drought, which may favor only some of the present species to persist [16]. Consequently, understanding and predicting how germination phenology changes in warmer climatic conditions is of imperative scientific and practical importance, because such information is helpful in devising appropriate conservation actions.

Although our understanding of how seeds germinate in the warmer world is not comprehensive across various ecosystems, we focus on the results available on alpine and arctic ecosystems. This by no means denotes that other ecosystems are less important; however, the effects of global warming have become more apparent in alpine regions with upward migration of plants being witnessed already [17-19], prompting a need to review the literature and use these lessons learned to plan conservation protocols. In addition, high altitude and high latitude regions are highly fragile ecosystems that are extremely susceptible to even a slight increase in temperature. Thus, these ecosystems are regarded as a "reliable indicator" for predicting the effects of climate change worldwide [19]. Secondly, unlike other ecosystems, global warming results in extinctions of arctic-alpine species, as these cold-adapted species migrate to higher altitudes and latitudes in search of diminishing suitable climate space $[9,17]$. Thirdly, we know little about the process of germination even under the current climate, as it has been long thought that alpine plants typically select vegetative reproduction, although there is growing consensus that seeds represent key survival mechanisms of alpine species [20].

Given that the appropriate conditions required to complete germination are extremely narrow for arctic-alpine species [21-23], many mechanisms have been evolved to synchronize the timing of germination with the short-growing season, so that the seedling establishment and plant growth are maximized $[21,22,24]$. There are a small but increasing number of studies addressing the possible effects of warming on germination ecology of alpine species [25-32]. However, the results of these studies have led to uncertainties in answering the important question: does a warmer alpine climate favor or hamper the germination of seeds? If one attempts to generalize seed germination response under warmer conditions, a great deal of heterogeneity results from evaluating data from different methods employed in each study. The overarching aim of this contribution is to outline methods used in studying the germination response of alpine/arctic seeds to increasing temperatures and provide a crucial reevaluation of their merits. In particular, we attempt to show that there are some inconsistencies in methods employed by previous studies affecting our ability to predict the real-life effects.

\section{Theoretical Predictions for Germination Response to Climate Change}

Climate change affects the seed germination and persistence of many seed bearing species across various environments, in an ecosystem-specific way [33-36]. This complex interface of species with the prevailing climatic condition often guides species to develop dormancy, which will be broken with a particular set of conditions following seed dispersal but before growing season $[3,5]$. In particular, the changing climate is affecting arctic-alpine species in numerous ways [37] and this effect is the result of many complex interactions between the different biological, hydrological, climatic, and edaphic components of the surrounding ecosystems [38]. Consequently, it is useful to untangle the different mechanisms affecting seeds in order to understand how climate change might alter germination success and whether the experimental investigations analysed later in this review adequately address all the critical aspects of climate change.

The key component of climate change is an increase in atmospheric temperature and changes of $+3.3^{\circ} \mathrm{C}$ in alpine regions have been predicted by the end of this century [39], potentially affecting seed development, persistence, and germination. This average masks a seasonal differential of $+2.7^{\circ} \mathrm{C}$ in the spring as opposed to $+3.8^{\circ} \mathrm{C}$ in the summers by 2098 and the coincidence of peak temperatures with crucial stages of dormancy breaking and germination has become the focus of experimental manipulations, some of which are reviewed later. Further, the increased temperatures have led to greater variability and less predictability in arctic-alpine weather patterns $[38,40]$, meaning that windows for suitable germination may become more or less frequent and will certainly become more irregular in their occurrence.

The indirect yet severe impacts of atmospheric warming on seeds of arctic-alpines include loss of early snow cover and late accumulation of snow in the autumn, fall of snow as precipitation, thin snow, increased windiness and resultant desiccation, high nocturnal temperature, and low diurnal temperature range. The surface reservoirs of frozen water, snow beds and ice sheets, are predicted to continue the general trend of recession [41, 42] that has already been recorded in arctic [38] and alpine [43] regions. Snow beds are of particular importance to seeds due to their capacity for ameliorating the harsh winter weather by insulating the soil surface below [44]. Dense snow cover ensures seeds overwinter in a "safe-repository" and the constant temperature experienced under snow cover, which is close to $0^{\circ} \mathrm{C}$, provides the right conditions for cold-stratification, breaking dormancy, and allowing seeds to germinate in the growing season $[24,45,46]$. Variation in snow thickness and lesser duration of snow cover may mean that the seeds maintain dormancy during the growing season. Seeds maintaining dormancy may be added to the "soil seed bank" and germinate in the future year or lose viability during persistence, thus affecting the dynamics of plant communities. Another outcome of snow bed loss is that colder temperatures are experienced by dispersed seeds and therefore elevated seed death due to ice formation in the internal tissues results. However, a third possible response is that earlier snow 
melt and later snow accumulation may also facilitate greater seed production in species that are normally restricted in size and, therefore, seed set due to a very short-growing season [47].

The accentuated seasonal variation together with markedly different temperatures is posing additional problems to the alpine seeds. Overall, the whole life-cycle of reproductive phase of plants from seed production to germination occurs in a warmer temperature [48-51]. The variation in maternal environment during seed maturation would have profound effect in determining the continued existence of a particular species [52]. Seeds mature with different levels of dormancy based on the location in which they mature, a phenomenon that could allow the seeds to judge duration required for dormancy break [53-55]. For example, seeds maturing at higher altitudes have deep PD and require longer duration of cold-stratification [24]. This is an adaptation as at higher altitudes snow cover is long and decrease in altitude correlates with lesser snow cover duration. However, climate change may alter both the temperature at which the seeds mature and the conditions at which these seeds persist in soil, as the length of snow cover will be greatly altered. The interaction between these factors affecting seed germination is less understood.

Soil temperatures of thawing permafrost regions are predicted to warm by $2-4^{\circ} \mathrm{C}[38,56]$ and this has particularly significant implications for seeds because this effectively deepens the soil horizon within which the seed may be dispersed. This may lead to greater burial depths and more infrequent exposure to conditions required for both dormancy breaking and germination [24] possibly leading to higher mortality of seeds over the long term.

Soil moisture has not been monitored in arctic regions but the surface water balance (which is closely correlated with soil moisture being the balance between precipitation and PET) has been shown to be in decline indicating drying of soils and this pattern is predicted to continue in alpine regions [39]. Water cycle changes in high latitudes and high altitudes also include increased groundwater infiltration where permafrost has thawed and ceases to be a physical barrier to water movement from the surface and surface flows such as rivers and streams that are predicted to increase with resultant greater erosion of soils particularly in the winter when there are more likely to be ungerminated viable seeds within these soils [57]. However, the general pattern of river and stream flow is difficult to predict because the aforementioned increase of water infiltration to underground aquifers might represent a diversion from surface flows and increased evapotranspiration may both result in reduced flow rates.

It is not yet known to what extent these varying factors will affect seed germination and it will undoubtedly be the case that the interplay between different influences may shift to favor net germination increase or decrease at very small scales. For this reason, it is imperative that experimental investigations simulate conditions without confounding their own results and are meticulous about reporting the conditions under which they germinate seeds or arctic-alpine species.

\section{Empirical Studies of Warming Effects on Seed Germination}

To identify any generalized trend of seed germination in high altitudes during warmer climate, we searched the ISI Web of Knowledge database for studies addressing the effect of warming temperature on seed germination in alpine/arctic ecosystem using key terms "alpine seed germination and climate change" or "arctic seed germination and climate change". This search resulted in 48 papers. We screened all the papers to identify the studies intended to determine the effects of warmer temperature on seed germination pattern. To be included in this work, seeds must be germinated at a warmer temperature and information should be presented about how these seeds were collected and any dormancy breaking treatments applied. With these as the criteria for selecting studies, we created a list by entering the species name and other parameters reported in Table 1 from 9 studies that met the criteria [25-31, 58, 59]. Briefly, each row contains information about how a particular species used in the original study was treated and multiple entries were made if the same species is treated under two different conditions. In this way, we were able to identify 191 cases belonging to 92 taxa with some overlap amongst nine studies [25-31, 58,59] which subjected seeds collected from alpine/arctic areas to a warming treatment in comparison to a control. In some cases, this control was a result of seeds being stored outside and subjected to natural conditions; in others, the control and warming treatments were created in cultivation to simulate predicted climatic warming.

We were able to include only five studies in their entirety; all the combination of treatments applied to different species listed in these five studies met our review requirements: 6 rows [27], 6 rows [31], 46 rows [28], 16 rows [26], and 90 rows [25]. In some other studies, only part of the investigation made it into our analysis as treatments were omitted because they could not be satisfactorily compared to the control. For example, Müller et al. [58] subjected seeds to four treatments of which only one is included in this summary, due to the lack of control in other treatments. Also, many species used in various treatments from this study showed no germination and based on their final germination percentages and comparison of species across various treatments only six species were included in the present work (6 rows). Shevtsova et al. [30] subjected their warming treatments using a Free Air Temperature Increase system to increase the soil temperature by $3^{\circ} \mathrm{C}$ over different combinations of subsequent time periods. Only the results from warming over the longest time period were included in this analysis (11 rows). In Klady et al. [29], seeds collected from five sites (5 rows) were tested, each having different soil characteristics; we consider germination was altered if there was a significant difference at least in one site. Hobbie and Chapin [59] performed their experiments with five species, but our analysis included only two species (2 rows) that germinated more than $5 \%$. 


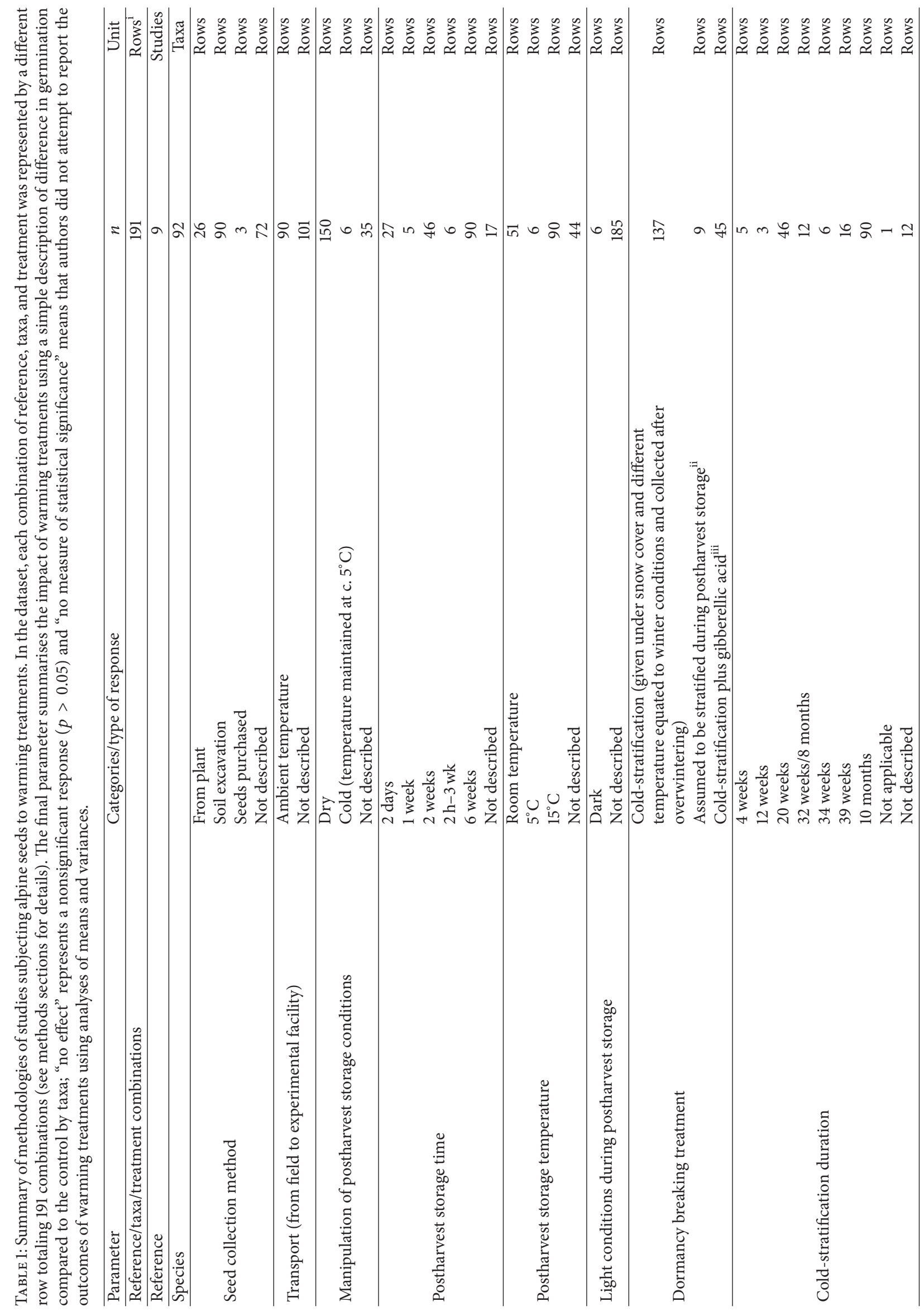




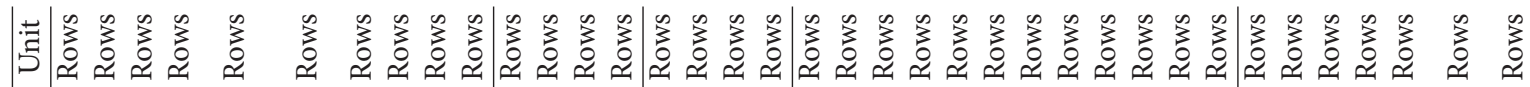

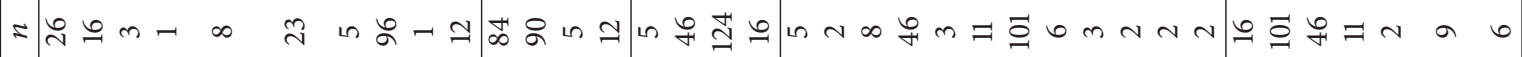
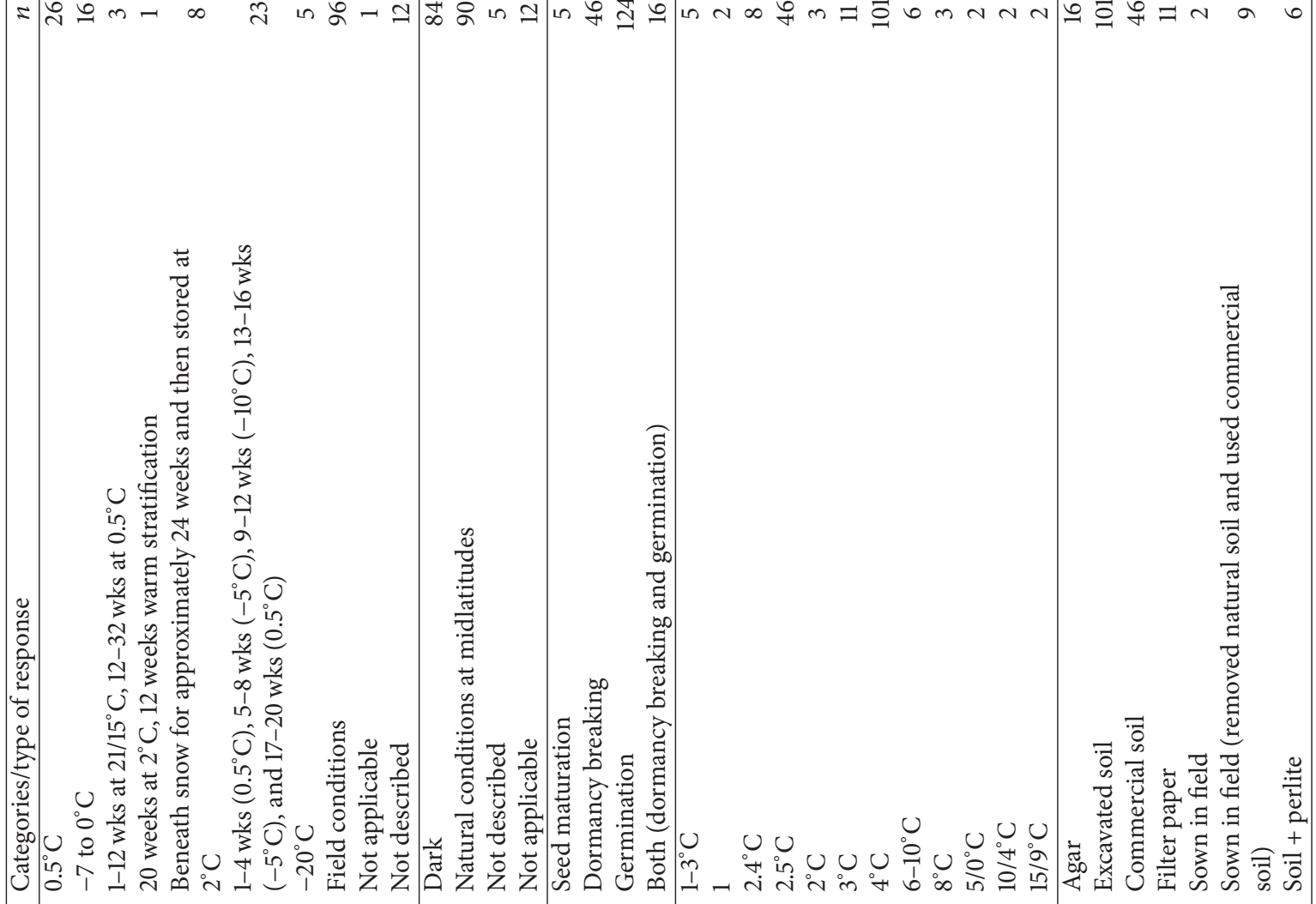

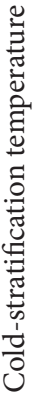

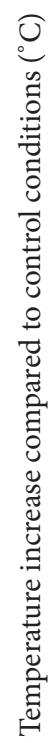

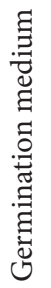




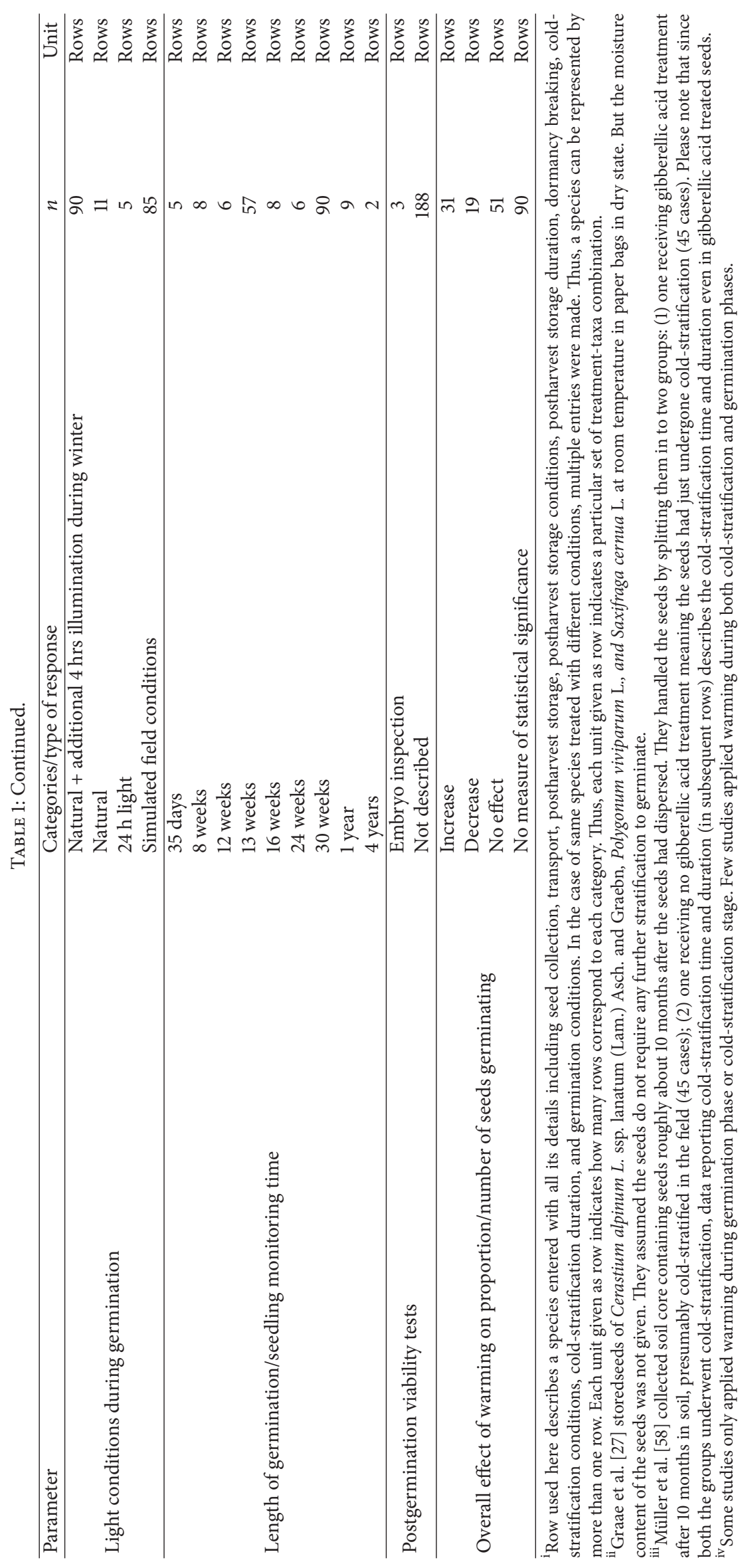




\section{Diversity of Methods Used in Warming Studies Affecting Our Capacity to Draw Generalized Conclusions}

Across the studies, a great diversity of methods exists in the way these seeds were handled from maturation to germination (Table 1). We discuss each of these in turn.

4.1. Seed Collection. The first factor to be considered is the seed collection method. Seeds may be collected directly from the plant, from the soil surface, or as part of a soil sample using coring or digging out whole turfs. The choice of collection technique has implications for the conclusions that can be drawn, but even within one of these methods, the potential for heterogeneity is great and prevents comparison of results from different studies.

Most of the studies collected fresh seeds that matured under current climatic conditions from soil or directly from plants at the end of maturation drying [26-28, 30, 31]. Seeds of most arctic and alpine species are shed during late summer or autumn and due to the requirement for dormancy breaking, which is satisfied during overwintering, these seeds do not germinate until spring $[24,54]$. After overwintering, these seeds come out of dormancy and acquire the ability to germinate at wide range of temperature ranging from as low as 5 to $30^{\circ} \mathrm{C}[22,24]$. However, germination is not an assured event every spring because of the unpredictability in the climatic conditions. As a result, many species are known to enter "soil seed banks" so that these seeds germinate in a later year having favorable conditions. Thus, simple collection of seeds from the plant or soil surface is expected to provide more information about germinating seeds from the "transient seed bank" (i.e., seeds live in soil for less than 5 years) but overlooks how seeds which entered the "persistent seed bank" (i.e., seeds live in soil for more than 5 years) are affected by global warming. Thus, an understanding of germination from recently shed seeds and seeds present in seed banks is necessary. To provide more information on the latter situation, Hoyle et al. [25] dug out $10 \mathrm{~cm}$ deep soil samples containing seeds and germinated them in glasshouse conditions to understand the effects of a warming climate on Australian alpine seeds persisted in soil. Therefore, this soil core contained seeds from both "transient" and "persistent" soil banks with the potential that recently shed seeds will become part of the persistent seed bank.

Overall, these methods of collecting seeds from soil or soil core matured under current environmental conditions ignore the fact that maternal environmental conditions in which the seeds mature will be warmer in the future climate. There is clear evidence to show that seeds matured in one microsite may have different physiology compared with other microsites and year $[60,61]$. Seeds of arctic-alpine species maturing under warmer conditions are likely to have different physiological characteristics including changes in dormancy status and seed size, than seeds matured under current conditions [50, 58, 62-64]. Interestingly, evidence of rapid climate change affecting the flowering phenology and the duration of seed maturation have been documented in other ecosystems [65-67]. The only investigation that included seeds matured in warmer climatic conditions from an alpine environment is the work by Klady et al. [29]. However, the postmaturation experiments included in their analysis unfortunately do not reflect that of the real-world future climatic conditions (see below).

4.2. Postharvest Storage. In many cases, seeds after collection were used almost immediately in the experiment (Table 1). Since the physiology of seeds might change during postharvest storage, the immediate use of seeds in the experiments provides some confidence that seeds have similar characteristics if they had persisted in soil. However, Hoyle et al. [25] air-dried and stored seeds for 6 weeks before incorporating their specimen in subsequent analysis (Table 1). It is therefore not known if the dormancy state of the seeds had altered by this process. Other cases recorded from all the 9 studies that reported to have stored seeds for a few weeks (see Table 1) might also have similar limitations. We believe that this will have been done to avoid seed decay but recommend that, whenever possible, direct transfer to experimental conditions is undertaken.

4.3. Dormancy Breaking. Other important factors that merit discussion are the conditions in which dormancy breaking was applied. Given the growing awareness that (1) seed collection time and/or methods influences the dormancy status of seeds and (2) methods used under ex situ conditions may not represent prevailing in situ conditions, ecologists are increasingly becoming conscious of employing ecologically meaningful dormancy breaking treatments. In their natural high latitude and high altitude environments, seeds are kept under snow cover in a fully imbibed state with constant temperature close to $0^{\circ} \mathrm{C}$. Thus, amongst several dormancy alleviation methods developed (e.g., cold-dry stratification and $\mathrm{GA}_{3}$ application), cold-wet stratification is regarded as ecologically relevant $[28,68]$. According to C. C. Baskin and J. M. Baskin [22], dormancy breaking with cold-stratification occurs only in imbibed seeds; if the seeds are completely dry (physiologically $<40 \% \mathrm{RH}$ ) the dormancy may not be broken. Liu et al. [68] tested the best dormancy breaking treatments in 489 Eastern Tibet Plateau alpine species and found coldwet conditions had resulted in better germination compared with dry warm or dry cold conditions.

In certain situations, seeds were allowed to overwinter in the field under current environmental conditions and subsequently germinated in glass house at a warmer temperature inferred from earlier literature [25, 27]. Many compelling new attempts have shown interest in studying the reverse, whereby the effects of various possible cold-stratification conditions that are predicted to result from a warming future climate are compared with the current winter conditions $[26,28]$. It has been assumed that these methods would inform us about the effects of a warmer climate on dormancy breaking. These approaches might need some degree of caution because of the variation in cold-stratification conditions applied in those studies. Of particular note is the variation in temperatures and duration of cold-stratification: from $-20^{\circ} \mathrm{C}$ to $0.5^{\circ} \mathrm{C}$ and 12 weeks to 10 months (Table 1). In the latter case, this was represented by the only soil excavation study [25]; soils were 
collected in the summer prior to seed set to ensure that seeds had been subjected to natural overwintering conditions. Of course, the 10 months between seed set and soil collection would constitute a time period longer than, and temperatures warmer than, that conventionally thought of as describing the cold-stratification period. On the other hand, Graae et al. [27] assumed seeds stored dry did not require any further stratification and thus did not specially apply any dormancy breaking treatment.

The variation in cold-stratification conditions used in these studies might be interpreted as an attempt by the study authors to equate experimental conditions to the locationspecific temperature variation predicted to prevail in the locations from which seeds were collected. However, this seems not to be the case as it does not explain the use of one constant temperature such as $-20^{\circ} \mathrm{C}$ [29], which does not reflect the real-world situation. There is a great deal of evidence to show that seeds under snow cover experience a constant and favorable temperature for dormancy break due to the insulating effects $[45,69]$. Although global warming is predicted in some scenarios, to reduce the snow thickness and also the snow cover duration [70], even under these situations, seeds are likely to be exposed to very low temperatures only for a short period of time. Furthermore, predictions for snow cover and duration are likely to very greatly. In addition to these difficulties, it is extremely challenging, if not impossible, to suggest whether optimal cold-stratification conditions might be met, as the temperature experienced by seeds in the soil is affected by not only the depth of the seeds but also the location. For example, at lower elevations, the seeds experience warmer soil temperatures than the same species at higher elevations. One meaningful approach would be to use data loggers to monitor the temperature and use these temperatures in the glass house (see recommendation).

Another approach to break dormancy in the seed samples collected from alpine/arctic locations is the use of gibberellic acid $\left(\mathrm{GA}_{3}\right)$ (Table 1). Hoyle et al. [25] applied $\mathrm{GA}_{3}$ to the seed samples that had undergone 10 months of cold-stratification in soil (45 rows in Table 1). $\mathrm{GA}_{3}$ treatment has important effects on dormancy alleviation, especially if the seeds have physiological dormancy (PD) [71]. GA 3 application in dormancy breaking studies estimates the level of PD, that is, nondeep, intermediate, and deep [22]. Hoyle et al. [25] showed that 17 out of 45 species only germinated if the dormancy is broken by applying between $5 \mathrm{mg} \mathrm{L}^{-1}$ and $1 \mathrm{gL}^{-1} \mathrm{GA}_{3}$ to their Australian alpine soil sample. This result indicates even after cold-stratification many species remained still dormant, which were broken with $\mathrm{GA}_{3}$. Although recurring studies are showing $\mathrm{PD}$ is a more common form of dormancy found in alpine species, it is not the only form of dormancy prevalent in alpine seeds. Soil samples dug out from random plots are also likely to contain seeds with physical, morphological, morphophysiological, and combinational dormancy of various level [22]. Thus, breaking dormancy with $\mathrm{GA}_{3}$ following cold-stratification in the field eventually underestimates the prevalence of other forms of dormancy in their sample. For example, species having an impermeable seed coat, that is, physical dormancy (PY), are less likely to break dormancy when treated with $\mathrm{GA}_{3}$. Further, they did not report any information about the nongerminated seeds at the time of terminating experiment. Thus, it is not known whether a proportion of seeds failed to overcome dormancy with $\mathrm{GA}_{3}$ treatment and remain nongerminated.

4.4. Germination. One of the fundamental problems with germinating multiple species ex situ is selecting an optimal temperature that is appropriate for all species. In general, the effects of global warming were predicted based on one constant temperature or, sometimes, an alternating temperature regime to mimic diurnal fluctuations to promote germination and compared with a warmer temperature inferred from literature [25]. Criticism of using one temperature to understand the alpine seed behavior has a long history (see Körner [21] for detailed discussion). It is often portrayed that freshly matured alpine seeds germinate well at higher temperature than at a lower temperature [22]. Consequently, many studies have attempted to germinate seeds at various combinations of higher temperature cycles, for example, $35^{\circ} / 25^{\circ} \mathrm{C}, 30^{\circ} / 20^{\circ} \mathrm{C}$, or $25^{\circ} / 15^{\circ} \mathrm{C}$ (e.g., [72]).

However, the situation in the natural environment is entirely different from this simplistic "one" temperature treatment. Temperature increases gradually following snow melt bringing growing conditions for some of the early germinating species $[21,23]$. In contrast, late germinating or hightemperature requiring species remain quiescent (sensu [73]) in the soil until the appropriate temperature for germination is attained. These differential temperature requirements are even apparent within genus; after stratification Carex remota resulted in more than $80 \%$ germination between 12 and $33^{\circ} \mathrm{C}$, whereas C. pendula germinated to $80 \%$ only at a higher temperature ranging between 24 and $33^{\circ} \mathrm{C}$, although few $C$. remota and C. pendula germinated at temperatures as low as $6^{\circ} \mathrm{C}$ and $9^{\circ} \mathrm{C}$, respectively [74]. Similarly, Marchand and Roach [75] showed germination of Juncus trifidus occurs only at relatively low temperatures between 12 and $23^{\circ} \mathrm{C}$, in contrast to the higher temperature $\left(15\right.$ and $\left.28^{\circ} \mathrm{C}\right)$ requirement in Potentilla tridentata. In species such as Arenaria groenlandica, germination occurred at a range of temperatures between 12 and $28^{\circ} \mathrm{C}$, although the percentage of germinated seeds differs with temperature.

In a warmer alpine climate, the decreased snow cover duration may not satisfy the stratification requirements evolved in seeds adapted at current environmental conditions. Similarly, late snow arrival could also shift seed germination time of some species, for example, Geum, Veronica, and Oxyria, to autumn (i.e., immediately after dispersal), instead of germinating after snow melt in spring as they do currently, probably also due to the seeds maturing in warmer conditions resulting in nondormant or conditionally dormant seeds [26]. Longer snow-free growing seasons expected from warmer climate in the future might increase the window of opportunity for germination, but the success of seedling establishment may be increased or decreased depending largely upon the location and species [30, 31, 59, 76, 77].

In addition, further limitations are incurred by the great range of temperature increases imposed after stratification during germination ranging from $1^{\circ} \mathrm{C}$ to diurnal peaks of $15^{\circ} \mathrm{C}$ above the control (Table 1). This range of temperatures is not 
a problem per se; the response of species to various warming treatments might be illuminating if the earlier treatment of seeds was more consistent. However, the potential for affecting the response of seeds prior to any experimentally controlled treatment is great given the variety of conditions applied during transport, postharvest storage, and pretreatment phases (Table 1). The apparent control of a particular temperature providing conditions for germination and the impact of warmer temperature occurring during the whole growing season affecting germination timing and emergence are also documented in other environments [13,78-80]. Thus, we emphasize that the response of seed germination in the future climate is more complex and increased research should shed more light on this subject.

4.5. Postgermination Viability Testing. A major problem with testing germination of many species at one temperature is that species requiring temperatures outside the given condition generally do not germinate. It is therefore apparently incorrect to conclude seed germination failure as nonviability $[81,82]$, but rather that the appropriate temperature for germination has not been possibly provided. Evaluating the nongerminated seeds after the germination tests by "tetrazolium test" has alternatively been proved useful in identifying viable but nongerminated seeds $[83,84]$. Whilst one cannot ignore the fact that it may not be possible to test the viability when experiments are performed in natural environment, we strongly emphasize whenever possible that future studies must test the nongerminated seeds at the end of germination experiments using tetrazolium test or other viability tests, as this approach could potentially serve as a reasonable way to identify the viable seeds that may require additional dormancy breaking treatments before they germinate. Thus, it is very surprising that 188 cases did not use any postviability assessments (Table 1).

4.6. Variation in Germination Response across Species Incorporated in Different Studies. The final parameter in Table 1 reports the impact of warming treatments on the proportion or number of seeds germinating. Thirty-one cases were identified where the impact of warming increased germination, 19 cases showed a decrease in germination after warming, and 51 showed no statistically significant difference to the control (Table 1). There are also inconsistencies in the time of application of warming. Only five cases applied warming treatment during seed maturation. But 46 cases were identified that applied the warming during stratification/dormancy breaking whilst 124 applied warming during the germination phase. The remaining 16 cases looked at warming during both the stratification and the germination phases (Table 1).

It should be noted that many taxa were included in several studies and only seven genera were represented by just one case each in the dataset. This serves to highlight our point that species response to warming appears to be inconsistent, but this conclusion is confounded by the diversity of methods employed and species response. For example, Dryas octopetala is represented four times in our dataset, in all cases germinated in soil; however, germination responds differentially to warming; at low increased temperatures $\left(2.5^{\circ} \mathrm{C}\right)$ no effect could be discerned [28] whilst at $3^{\circ} \mathrm{C}$ the response was negative (i.e., less germination). When the warming treatment varied $6-10^{\circ} \mathrm{C}$ above the control, the response was positive with Dryas octopetala showing increased germination [30]. Besides the variation in temperature used in the original studies possibly to determine the effects of different warming temperature on seed germination, another possible reason for the lack of consistent results in this species might also be due to the variation in cold-stratification duration and temperature applied to break dormancy, c.34 weeks in field [58] compared to 24 months under snow cover [30] and $0.5^{\circ} \mathrm{C}$ for $20 \mathrm{wks}$ or $1-4 \mathrm{wks}\left(0.5^{\circ} \mathrm{C}\right), 5-8 \mathrm{wks}\left(-5^{\circ} \mathrm{C}\right), 13-16 \mathrm{wks}$ $\left(-10^{\circ} \mathrm{C}\right)$, and $17-20 \mathrm{wks}\left(0.5^{\circ} \mathrm{C}\right)$ [28]. Similarly, Vaccinium uliginosum was reported to germinate higher [27], lower [28], or at the same level $[28,30]$ at an increased temperature. Although the difference in increased temperature range used in their studies appears to be the reason for such variation in germination response, the disparity of cold-stratification treatments employed in those studies also plays an important role contributing to the mixed results.

Similar conflicting patterns also exist in numerous other species. Germinating Betula pubescens ssp. czerepanovii at $2.5^{\circ} \mathrm{C}$ above current temperature level did not have any effect on germination [28], but when the temperature rose $3^{\circ} \mathrm{C}$ above current level the final germination percentage was significantly reduced [30]. However, accepting this result is at least partly perplexed by the dormancy breaking duration and conditions employed in those studies. Milbau et al. [28] used sequential dormancy breaking conditions: $1-4 \mathrm{wks}$ $\left(0.5^{\circ} \mathrm{C}\right), 5-8$ wks $\left(-5^{\circ} \mathrm{C}\right), 13-16$ wks $\left(-10^{\circ} \mathrm{C}\right)$, and $17-20$ wks $\left(0.5^{\circ} \mathrm{C}\right)$, whereas Shevtsova et al. [30] stored seeds beneath snow cover for approximately 24 weeks and then stored at $2^{\circ} \mathrm{C}$ (for an unknown period of time) before germinating them. For Empetrum hermaphroditum, a $2.5^{\circ} \mathrm{C}$ increase in temperature has no significant effect on germination [28], but when temperature increases $10 / 4,15 / 9$, and $5 / 0^{\circ} \mathrm{C}$ (day/night) compared to control the germination significantly improved [27]. One is tempted to conjecture that breaking dormancy in E. hermaphroditum by cold-stratification and incubating the seeds at higher temperature may result in higher germination percentage, but what effect global warming could have on dormancy breaking phase was not addressed by Graae et al. [27]. Seeds of Epilobium angustifolium germinated to a lesser percentage both when kept under snow cover [30] and after sequential dormancy breaking temperatures [28], but applying cold-stratification at a constant temperature of $0.5^{\circ} \mathrm{C}$ improved germination when tested at $2.5^{\circ} \mathrm{C}$ higher than current temperature, explicitly indicating the way by which cold-stratification is applied determines the final germination percentage. Similar inconsistent patterns were also found in Vaccinium uliginosum, as more germination was reported by Graae et al. [27], but lesser germination percentage was reported by Milbau et al. [28].

Because of these conflicting patterns, we agree with the summaries of various authors included here that response to warming is a species-specific impact which cannot be generalized across functional type or regional flora. The nine studies included in this analysis used seeds maturing in different locations: Alaska [59], Australia [25], Canada [58], 
Greenland [27], Sweden [28, 30], and Italy [26], thus possibly having different initial dormancy and germination ability as reviewed by Jaganathan et al. [24], leading to a difference in the germination pattern. However, we also add that the variable response we identified even using coarse measures of increased or decreased germination within species shows that the species response is highly dependent on the experimental set-up. This fact undermines any attempt to extrapolate experimental responses to the real world and makes predictions difficult, if not impossible, using existing data. Thus, any future attempts to make real predictions of alpine seed germination should consider the fact that, in the warmer world, seeds will be exposed to higher temperatures from flowering to germination. Indeed the whole life-cycle of arctic-alpine plants will be happening at a higher temperature. Thus, using season-specific temperature change (predicted in warmer arctic and alpine soils) to break dormancy and germination of seeds matured in a warmer conditions would provide more realistic insights.

Some general recommendations can be made based on the lessons learned from previous studies. These are common guidelines, but it is evident that studies are increasing without paying particular attention to these issues. Thus, we believe that following these recommendations might help better predict the effects of global warming on high latitude and high altitude ecosystems.

(1) Efforts must be taken to grow plants in higher temperatures and collect the seeds that matured in a warmer climate or establish permanent plots (see Elkin et al. [9] for detailed information on how to establish long-term plots) and monitor the process of seed maturation and germination in field conditions. ITEX has already taken steps to monitor the changes in seed characteristics grown in a warmer temperature by growing plants in warmer conditions; we suggest this approach should also be extended to germination and seedling phase.

(2) In case of planning experiments ex situ, seeds must be collected from both plants and freshly shed seeds from the uppermost soil surface (most likely mid-tolate autumn). Although seeds of most alpine plants are small and collecting them at the time of maturity is complex, most of the studies reviewed here collected seeds at the time of maturity indicating collection of freshly matured seeds is possible. In addition, complementary studies must be performed by collecting the soil core and determining the depths to which the targeted species has been buried. Replication should aim to represent the spatial heterogeneity of the system using the scale of plant community patches as a guide. Researchers should be aware that an appropriate system of randomly located plots (using a stratified sampling procedure if necessary) with a set number of cores from within each plot would constitute proper replication.

(3) Transport seeds and soil samples containing seeds as quickly as possible to conditions that mimic natural environmental changes (i.e., the current conditions or control and the warming treatment(s), both with appropriate photoperiods) in which seeds will be allowed to experience the natural conditions; that is, "temperature control" chambers capable of lowering temperatures to subzero level. However, prior to transporting the seeds, soil from cores should be pooled and mixed by plot and kept moist at levels that mimic natural conditions. Whenever possible, moist soil must be used as germinating medium. This also helps us to monitor the process of germination until seedling stage.

(4) It is recommended to split the samples collected both from plants and from soil core into various subsamples that are treated to different temperature regimes in parallel. That is to say, one chamber must be designed to match with the temperature of current alpine climate. Other(s) should replicate soil temperature according to recent projections relevant to the location of seed collection. It is well-known that maternal effect may determine the physiological state of seeds, thus affecting the level of dormancy and germination temperature in the freshly collected seeds $[24,85]$. To avoid this problem, we suggest using a data logger to measure the soil temperature of seed collected site and follow this temperature in the chamber. Thus, seeds experience field conditions but in the chamber. If this is done over long time periods, that is, 1 to 2 years, the pattern of germination and dormancy breaking under the current environmental conditions can be determined. Using the other subsamples in additional chambers, warming treatments can be applied, that is, current temperature determined from data loggers + temperature replicating the projections under warmer conditions, for example, $2^{\circ} \mathrm{C}$. In this way, seeds experience warmer climate from dormancy breaking to germination.

(5) Seeds need to be monitored regularly to ensure that germination does not go unnoticed. Seedlings should be identified as soon as possible and removed or grown in a different medium until identification is possible.

(6) When the long-term experiment seems to be finished, the remaining seeds should be sieved from the soil and checked for viability, for example, using the tetrazolium test. Further, we suggest using tetrazolium test in freshly collected seeds, after dormancy breaking step (if applied separately) and possibly at the end of germination to compare the number of seeds deemed viable.

\section{Competing Interests}

The authors declare that they have no competing interests.

\section{Acknowledgments}

This work would not have been made possible without the help of Ms. Xiao Qun, who spent hours in checking 
the database created. The authors thank all researchers who provided valuable comments on earlier draft of this paper.

\section{References}

[1] M. Fenner and K. Thompson, The Ecology of Seeds, Cambridge University Press, 2005.

[2] R. L. Long, M. J. Gorecki, M. Renton et al., “The ecophysiology of seed persistence: a mechanistic view of the journey to germination or demise," Biological Reviews, vol. 90, no. 1, pp. 31-59, 2015

[3] W. E. Finch-Savage and G. Leubner-Metzger, "Seed dormancy and the control of germination," New Phytologist, vol. 171, no. 3, pp. 501-523, 2006.

[4] D. L. Venable, "Bet hedging in a guild of desert annuals," Ecology, vol. 88, no. 5, pp. 1086-1090, 2007.

[5] C. G. Willis, C. C. Baskin, J. M. Baskin et al., "The evolution of seed dormancy: environmental cues, evolutionary hubs, and diversification of the seed plants," New Phytologist, vol. 203, no. 1, pp. 300-309, 2014.

[6] J. Plue, P. De Frenne, K. Acharya et al., "Climatic control of forest herb seed banks along a latitudinal gradient," Global Ecology and Biogeography, vol. 22, no. 10, pp. 1106-1117, 2013.

[7] A. Cochrane, C. J. Yates, G. L. Hoyle, and A. B. Nicotra, "Will among-population variation in seed traits improve the chance of species persistence under climate change?" Global Ecology and Biogeography, vol. 24, no. 1, pp. 12-24, 2015.

[8] G.-R. Walther, E. Post, P. Convey et al., "Ecological responses to recent climate change," Nature, vol. 416, no. 6879, pp. 389-395, 2002.

[9] C. Elkin, A. G. Gutiérrez, S. Leuzinger et al., "A $2{ }^{\circ} \mathrm{C}$ warmer world is not safe for ecosystem services in the European Alps," Global Change Biology, vol. 19, no. 6, pp. 1827-1840, 2013.

[10] B. Luna, B. Pérez, I. Torres, and J. M. Moreno, "Effects of incubation temperature on seed germination of mediterranean plants with different geographical distribution ranges," Folia Geobotanica, vol. 47, no. 1, pp. 17-27, 2012.

[11] P. De Frenne, B. J. Graae, J. Brunet et al., “The response of forest plant regeneration to temperature variation along a latitudinal gradient," Annals of Botany, vol. 109, no. 5, pp. 1037-1046, 2012.

[12] L. R. Iverson, M. W. Schwartz, and A. M. Prasad, "How fast and far might tree species migrate in the eastern United States due to climate change?" Global Ecology and Biogeography, vol. 13, no. 3, pp. 209-219, 2004.

[13] R. P. Neilson, L. F. Pitelka, A. M. Solomon et al., "Forecasting regional to global plant migration in response to climate change," BioScience, vol. 55, no. 9, pp. 749-759, 2005.

[14] M. K. J. Ooi, T. D. Auld, and A. J. Denham, "Climate change and bet-hedging: interactions between increased soil temperatures and seed bank persistence," Global Change Biology, vol. 15, no. 10, pp. 2375-2386, 2009.

[15] F. Giorgi and P. Lionello, "Climate change projections for the Mediterranean region," Global and Planetary Change, vol. 63, no. 2-3, pp. 90-104, 2008.

[16] J. Kreyling, "Winter climate change: a critical factor for temperate vegetation performance," Ecology, vol. 91, no. 7, pp. 19391948, 2010.

[17] J.-P. Theurillat and A. Guisan, "Potential impact of climate change on vegetation in the European Alps: a review," Climatic Change, vol. 50, no. 1-2, pp. 77-109, 2001.
[18] G.-R. Walther, S. Beißner, and C. A. Burga, "Trends in the upward shift of alpine plants," Journal of Vegetation Science, vol. 16, no. 5, pp. 541-548, 2005.

[19] S. Dullinger, T. Dirnböck, and G. Grabherr, "Modelling climate change-driven treeline shifts: relative effects of temperature increase, dispersal and invasibility," Journal of Ecology, vol. 92, no. 2, pp. 241-252, 2004.

[20] T. A. Forbis, "Seedling demography in an alpine ecosystem," American Journal of Botany, vol. 90, no. 8, pp. 1197-1206, 2003.

[21] C. Körner, Alpine Plant Life: Functional Plant Ecology of High Mountain Ecosystems, Springer, 2003.

[22] C. C. Baskin and J. M. Baskin, Seeds: Ecology, Biogeography, and Evolution of Dormancy and Germination, Elsevier, San Diego, Calif, USA, 2nd edition, 2014.

[23] W. D. Billings and H. A. Mooney, "The ecology of arctic and alpine plants," Biological Reviews, vol. 43, no. 4, pp. 481-529, 1968.

[24] G. K. Jaganathan, S. E. Dalrymple, and B. Liu, "Towards an understanding of factors controlling seed bank composition and longevity in the alpine environment," The Botanical Review, vol. 81, no. 1, pp. 70-103, 2015.

[25] G. L. Hoyle, S. E. Venn, K. J. Steadman et al., "Soil warming increases plant species richness but decreases germination from the alpine soil seed bank," Global Change Biology, vol. 19, no. 5, pp. 1549-1561, 2013.

[26] A. Mondoni, G. Rossi, S. Orsenigo, and R. J. Probert, "Climate warming could shift the timing of seed germination in alpine plants," Annals of Botany, vol. 110, no. 1, pp. 155-164, 2012.

[27] B. J. Graae, I. G. Alsos, and R. Ejrnaes, "The impact of temperature regimes on development, dormancy breaking and germination of dwarf shrub seeds from arctic, alpine and boreal sites," Plant Ecology, vol. 198, no. 2, pp. 275-284, 2008.

[28] A. Milbau, B. J. Graae, A. Shevtsova, and I. Nijs, "Effects of a warmer climate on seed germination in the subarctic," Annals of Botany, vol. 104, no. 2, pp. 287-296, 2009.

[29] R. A. Klady, G. H. R. Henry, and V. Lemay, "Changes in high arctic tundra plant reproduction in response to long-term experimental warming," Global Change Biology, vol. 17, no. 4, pp. 16111624, 2011.

[30] A. Shevtsova, B. J. Graae, T. Jochum et al., "Critical periods for impact of climate warming on early seedling establishment in subarctic tundra," Global Change Biology, vol. 15, no. 11, pp. 2662-2680, 2009.

[31] B. J. Graae, R. Ejrnæs, F. L. Marchand et al., "The effect of an early-season short-term heat pulse on plant recruitment in the Arctic," Polar Biology, vol. 32, no. 8, pp. 1117-1126, 2009.

[32] M. Drescher and S. C. Thomas, "Snow cover manipulations alter survival of early life stages of cold-temperate tree species," Oikos, vol. 122, no. 4, pp. 541-554, 2013.

[33] C. M. D’Antonio and P. M. Vitousek, "Biological invasions by exotic grasses, the grass/fire cycle, and global change," Annual Review of Ecology and Systematics, vol. 23, no. 1, pp. 63-87, 1992.

[34] D. J. Kriticos, R. W. Sutherst, J. R. Brown, S. W. Adkins, and G. F. Maywald, "Climate change and the potential distribution of an invasive alien plant: Acacia nilotica ssp. indica in Australia," Journal of Applied Ecology, vol. 40, no. 1, pp. 111-124, 2003.

[35] R. Condit, S. P. Hubbell, and R. B. Foster, "Changes in tree species abundance in a neotropical forest: impact of climate change," Journal of Tropical Ecology, vol. 12, no. 2, pp. 231-256, 1996. 
[36] I. Ibáñez, J. S. Clark, S. LaDeau, and J. Hille Ris Lambers, "Exploiting temporal variability to understand tree recruitment response to climate change," Ecological Monographs, vol. 77, no. 2, pp. 163-177, 2007.

[37] V. F. Briceño, G. L. Hoyle, and A. B. Nicotra, "Seeds at risk: how will a changing alpine climate affect regeneration from seeds in alpine areas?" Alpine Botany, vol. 125, no. 2, pp. 59-68, 2015.

[38] L. D. Hinzman, N. D. Bettez, W. R. Bolton et al., "Evidence and implications of recent climate change in Northern Alaska and other Arctic regions," Climatic Change, vol. 72, no. 3, pp. 251298, 2005.

[39] A. Gobiet, S. Kotlarski, M. Beniston, G. Heinrich, J. Rajczak, and M. Stoffel, "21st century climate change in the European Alps-a review," Science of the Total Environment, vol. 493, pp. 1138-1151, 2014.

[40] G. Parolo and G. Rossi, "Upward migration of vascular plants following a climate warming trend in the Alps," Basic and Applied Ecology, vol. 9, no. 2, pp. 100-107, 2008.

[41] J. P. Dedieu, A. Lessard-Fontaine, G. Ravazzani, E. Cremonese, G. Shalpykova, and M. Beniston, "Shifting mountain snow patterns in a changing climate from remote sensing retrieval," Science of the Total Environment, vol. 493, pp. 1267-1279, 2014.

[42] M. Beniston, H. F. Diaz, and R. S. Bradley, "Climatic change at high elevation sites: an overview," Climatic Change, vol. 36, no. 3-4, pp. 233-251, 1997.

[43] S. Chersich, K. Rejšek, V. Vranová, M. Bordoni, and C. Meisina, "Climate change impacts on the Alpine ecosystem: an overview with focus on the soil," Journal of Forest Science, vol. 61, no. 11, pp. 496-514, 2015.

[44] R. G. Björk and U. Molau, "Ecology of alpine snowbeds and the impact of global change," Arctic, Antarctic, and Alpine Research, vol. 39, no. 1, pp. 34-43, 2007.

[45] R. J. Williams, "Patterns of air temperature and accumulation of snow in subalpine heathlands and grasslands on the Bogong High Plains, Victoria," Australian Journal of Ecology, vol. 12, no. 2, pp. 153-163, 1987.

[46] K. D. Sommerville, A. J. Martyn, and C. A. Offord, "Can seed characteristics or species distribution be used to predict the stratification requirements of herbs in the Australian Alps?" Botanical Journal of the Linnean Society, vol. 172, no. 2, pp. 187204, 2013.

[47] Y. Vitasse, S. Delzon, C. C. Bresson, R. Michalet, and A. Kremer, "Altitudinal differentiation in growth and phenology among populations of temperate-zone tree species growing in a common garden," Canadian Journal of Forest Research, vol. 39, no. 7, pp. 1259-1269, 2009.

[48] M. V. Price and N. M. Waser, "Effects of experimental warming on plant reproductive phenology in a subalpine meadow," Ecology, vol. 79, no. 4, pp. 1261-1271, 1998.

[49] C.-H. A. Wahren, M. D. Walker, and M. S. Bret-Harte, "Vegetation responses in Alaskan arctic tundra after 8 years of a summer warming and winter snow manipulation experiment," Global Change Biology, vol. 11, no. 4, pp. 537-552, 2005.

[50] C. Galen and M. L. Stanto, "Short-term responses of alpine buttercups to experimental manipulations of growing season length," Ecology, vol. 74, no. 4, pp. 1052-1058, 1993.

[51] G. Kudo and A. S. Hirao, "Habitat-specific responses in the flowering phenology and seed set of alpine plants to climate variation: implications for global-change impacts," Population Ecology, vol. 48, no. 1, pp. 49-58, 2006.
[52] G. Bernareggi, M. Carbognani, A. Petraglia, and A. Mondoni, "Climate warming could increase seed longevity of alpine snowbed plants," Alpine Botany, vol. 125, no. 2, pp. 69-78, 2015.

[53] B. Liebst and J. Schneller, "Seed dormancy and germination behaviour in two Euphrasia species (Orobanchaceae) occurring in the Swiss Alps," Botanical Journal of the Linnean Society, vol. 156, no. 4, pp. 649-656, 2008.

[54] E. Schwienbacher, J. A. Navarro-Cano, G. Neuner, and B. Erschbamer, "Seed dormancy in alpine species," Flora: Morphology, Distribution, Functional Ecology of Plants, vol. 206, no. 10, pp. 845-856, 2011.

[55] I. Wagner and A. M. Simons, "Intraspecific divergence in seed germination traits between high- and low-latitude populations of the arctic-alpine annual Koenigia islandica," Arctic, Antarctic, and Alpine Research, vol. 40, no. 1, pp. 233-239, 2008.

[56] W. Haeberli and M. Beniston, "Climate change and its impacts on glaciers and permafrost in the Alps," Ambio, vol. 27, no. 4, pp. 258-265, 1998.

[57] E. J. Scherff, C. Galen, and M. L. Stanton, "Seed dispersal, seedling survival and habitat affinity in a snowbed plant: Limits to the distribution of the snow buttercup, Ranunculus adoneus," Oikos, vol. 69, no. 3, pp. 405-413, 1994.

[58] E. Müller, E. J. Cooper, and I. G. Alsos, "Germinability of arctic plants is high in perceived optimal conditions but low in the field," Botany, vol. 89, no. 5, pp. 337-348, 2011.

[59] S. E. Hobbie and F. S. Chapin, "An experimental test of limits to tree establishment in Arctic tundra," Journal of Ecology, vol. 86, no. 3, pp. 449-461, 1998.

[60] J. Beckstead, S. E. Meyer, and P. S. Allen, "Bromus tectorum seed germination: between-population and between-year variation," Canadian Journal of Botany, vol. 74, no. 6, pp. 875-882, 1996.

[61] G. K. Jaganathan, "Influence of maternal environment in developing different levels of physical dormancy and its ecological significance," Plant Ecology, vol. 217, no. 1, pp. 71-79, 2016.

[62] G. H. R. Henry and U. Molau, "Tundra plants and climate change: the International Tundra Experiment (ITEX)," Global Change Biology, vol. 3, no. 1, pp. 1-9, 1997.

[63] J. Walck and K. Dixon, "Time to future-proof plants in storage," Nature, vol. 462, no. 7274, p. 721, 2009.

[64] A. M. Arft, M. D. Walker, J. Gurevitch et al., "Responses of Tundra plants to experimental warming: meta-analysis of the international tundra experiment," Ecological Monographs, vol. 69, no. 4, pp. 491-511, 1999.

[65] S. J. Franks, S. Sim, and A. E. Weis, "Rapid evolution of flowering time by an annual plant in response to a climate fluctuation," Proceedings of the National Academy of Sciences of the United States of America, vol. 104, no. 4, pp. 1278-1282, 2007.

[66] Ø. Johnsen, C. G. Fossdal, N. Nagy, J. MØlmann, O. G. Dæhlen, and T. SkrØppa, "Climatic adaptation in Picea abies progenies is affected by the temperature during zygotic embryogenesis and seed maturation," Plant, Cell \& Environment, vol. 28, no. 9, pp. 1090-1102, 2005.

[67] A. Hedhly, J. I. Hormaza, and M. Herrero, "Global warming and sexual plant reproduction," Trends in Plant Science, vol. 14, no. 1, pp. 30-36, 2009.

[68] K. Liu, J. M. Baskin, C. C. Baskin et al., "Effect of storage conditions on germination of seeds of 489 species from high elevation grasslands of the eastern Tibet Plateau and some implications for climate change," American Journal of Botany, vol. 98, no. 1, pp. 12-19, 2011. 
[69] C. Lütz, Plants in Alpine Regions: Cell Physiology of Adaption and Survival Strategies, Springer, Vienna, Austria, 2011.

[70] S. Wipf, V. Stoeckli, and P. Bebi, "Winter climate change in alpine tundra: plant responses to changes in snow depth and snowmelt timing," Climatic Change, vol. 94, no. 1-2, pp. 105-121, 2009.

[71] S. Turner and D. Merritt, "Seed germination and dormancy," in Plant Germplasm Conservation in Australia: Stratergies and Guidelines for Developing, Managing an Utlizing Ex Situ Collection, C. A. Offord and P. F. Meagher, Eds., Australian Network for Plant Conservation, Canberra, Australia, 2009.

[72] Y. Shimono and G. Kudo, "Comparisons of germination traits of alpine plants between fellfield and snowbed habitats," Ecological Research, vol. 20, no. 2, pp. 189-197, 2005.

[73] A. J. Murdoch and R. H. Ellis, "Dormancy, viability and longevity," in Seeds: The Ecology of Regeneration in Plant Communities, M. Fenner, Ed., pp. 183-214, CABI Publishing, Wallingford, UK, 2000.

[74] M. Brändel and W. Schütz, "Temperature effects on dormancy levels and germination in temperate forest sedges (Carex)," Plant Ecology, vol. 176, no. 2, pp. 245-261, 2005.

[75] P. J. Marchand and D. A. Roach, "Reproductive strategies of pioneering alpine species: seed production, dispersal, and germination," Arctic and Alpine Research, vol. 12, no. 2, pp. 137-146, 1980.

[76] R. Crawford, Plants at the Margin: Ecological Limits and Climate Change, Cambridge University Press, Cambridge, UK, 2008.

[77] J. L. Walck, S. N. Hidayati, K. W. Dixon, K. Thompson, and P. Poschlod, "Climate change and plant regeneration from seed," Global Change Biology, vol. 17, no. 6, pp. 2145-2161, 2011.

[78] N. M. Nadkarni and R. Solano, "Potential effects of climate change on canopy communities in a tropical cloud forest: an experimental approach," Oecologia, vol. 131, no. 4, pp. 580-586, 2002.

[79] F. T. Short and H. A. Neckles, "The effects of global climate change on seagrasses," Aquatic Botany, vol. 63, no. 3-4, pp. 169196, 1999.

[80] M. B. Davis, R. G. Shaw, and J. R. Etterson, "Evolutionary responses to changing climate," Ecology, vol. 86, no. 7, pp. 17041714, 2005.

[81] L. Bliss, "Seed germination in arctic and alpine species," Arctic, vol. 11, no. 3, pp. 180-188, 1958.

[82] M. T. K. Arroyo, L. A. Cavieres, C. Castor, and A. M. Humaña, "Persistent soil seed bank and standing vegetation at a high alpine site in the central chilean andes," Oecologia, vol. 119, no. 1, pp. 126-132, 1999.

[83] L. A. Cavieres and M. T. K. Arroyo, "Seed germination response to cold stratification period and thermal regime in Phacelia secunda (Hydrophyllaceae) - altitudinal variation in the Mediterranean Andes of central Chile," Plant Ecology, vol. 149, no. 1, pp. 1-8, 2000.

[84] L. Giménez-Benavides, A. Escudero, and F. Pérez-García, "Seed germination of high mountain Mediterranean species: altitudinal, interpopulation and interannual variability," Ecological Research, vol. 20, no. 4, pp. 433-444, 2005.

[85] S. E. Meyer, S. G. Kitchen, and S. L. Carlson, "Seed germination timing patterns in Intermountain Penstemon (Scrophulariaceae)," American Journal of Botany, vol. 82, no. 3, pp. 377-389, 1995. 

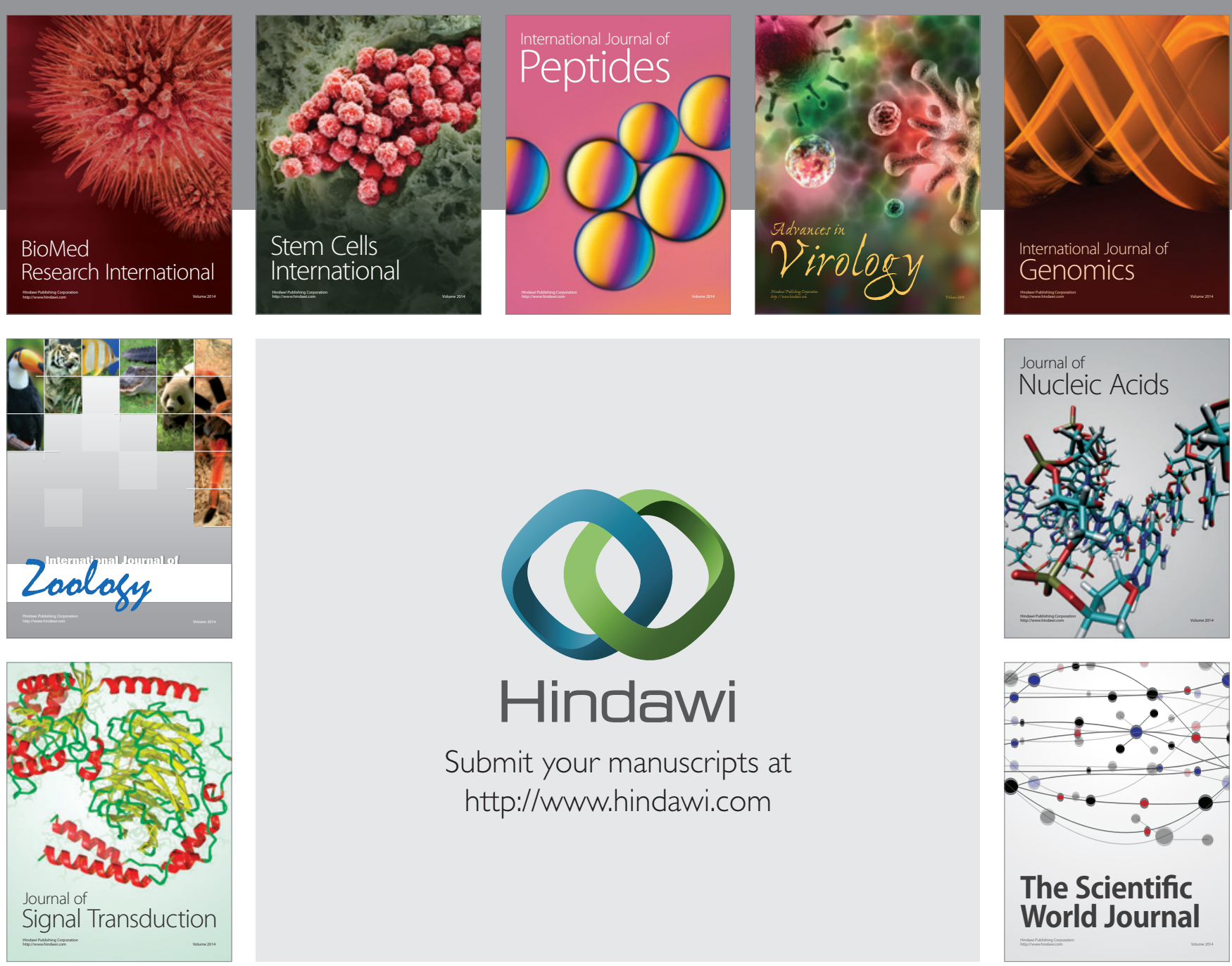

Submit your manuscripts at

http://www.hindawi.com
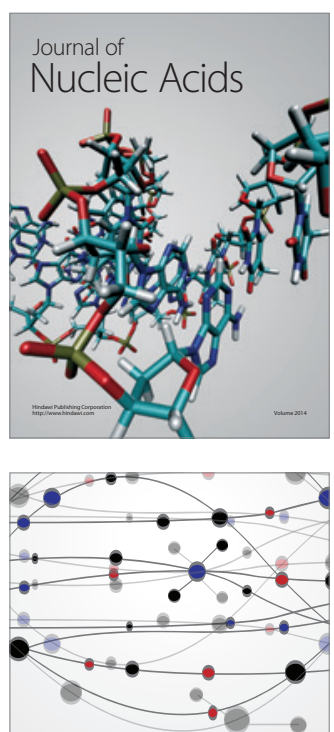

The Scientific World Journal
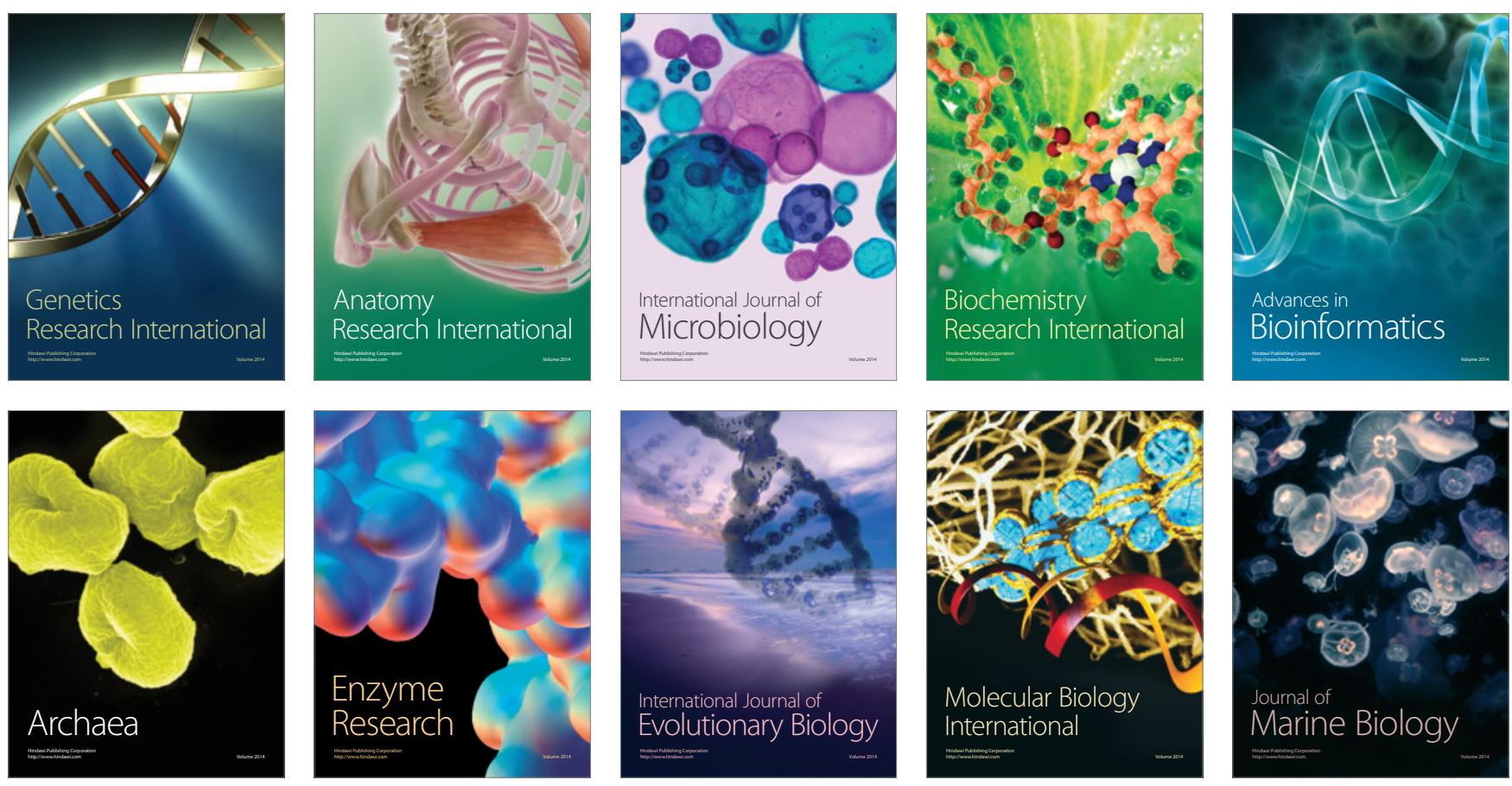